\title{
A CIDADE INTERROMPIDA: UMA ANÁLISE CRÍTICA DA INTERVENÇÃO ESTADUAL PROVOCADA PELO TRIBUNAL DE CONTAS
}

\section{THE INTERRUPTED CITY: A CRITICAL ANALYSIS OF THE STATE INTERVENTION CAUSED BY THE COURT OF ACCOUNTS}

\author{
Elisa Helena Lesqueves Galante ${ }^{1}$ \\ Adriano Sant'Ana Pedra²
}

\section{Resumo}

O estudo distingue a intervenção no ente federado no vigente modelo tridimensional da federação brasileira como fundamento para analisar a participação do Tribunal de Contas na instauração do processo de intervenção estadual no Município. A partir de um estudo qualitativo e dedutivo, são identificadas as Constituições estaduais que ampliaram as condições materiais ou formais para a intervenção estadual e os julgamentos das intervenções estaduais com fundamento nesses textos constitutivos dos Estados-membros da federação. Mediante pesquisa na doutrina jurídica e em precedentes do Supremo Tribunal Federal constata-se que o Tribunal de Contas não possui legitimidade constitucional para iniciar o processo de intervenção no ente federado. De forma contrária, o procedimento tem sido adotado, o que proporciona ausência de segurança no federalismo brasileiro com a mitigação da autonomia do Município originada pela intervenção no ente federado por ato de gestão do agente político, o que acarreta uma dupla vitimização do ente federado.

Palavras-chave: autonomia; federalismo; intervenção; município; tribunal de contas.

\begin{abstract}
This paper distinguishes intervention in federal entity, in the current three-dimensional model of the Brazilian federation, as a basis to analyze the main goal: the role of the Court of Accounts to require state intervention process against the Municipality. The article identifies, by a qualitative and deductive study, state constitutions which expanded material or formal conditions for state intervention as well as judgments of state interventions based on these state constitutional texts. By analyzing jurist's opinion and judicial precedents of the Federal Supreme Court, one can conclude that the Court of Accounts has no constitutional legitimacy to start intervention process against these federal entities. Nevertheless, such a procedure has been adopted, which provides an absence of safety in Brazilian federalism because of the mitigation of the municipal autonomy caused by intervention in the federal entity by an act of management of a political agent, which results a double victimization of the federal entity.
\end{abstract}

Keywords: autonomy; federalism; intervention; municipality; court of accounts.

\footnotetext{
${ }^{1}$ Doutoranda em Direitos e Garantias Fundamentais (FDV); Mestre em Direito - Políticas Públicas e Processo (FDC); membro do grupo de pesquisa "Efetivação dos Direitos Fundamentais pelo Estado" (FDV); Professora da Faculdade de Direito de Cachoeiro de Itapemirim (FDCl); Procuradora Municipal e Advogada. E-mail: lenagalante@hotmail.com

${ }^{2}$ Doutor em Direito Constitucional (PUC/SP). Mestre em Direitos e Garantias Fundamentais (FDV). Professor do Programa de Pós-Graduação Stricto Sensu - Mestrado e Doutorado - em Direitos e Garantias Fundamentais da FDV. Membro do grupo de pesquisa "Estado, Democracia Constitucional e Direitos Fundamentais" (FDV). Procurador Federal. E-mail: adrianopedra@fdv.br
} 


\section{INTRODUÇÃO}

A intervenção no ente federado - expressão que aqui se adota em razão da natureza singular do modelo tridimensional da federação brasileira - é ato político excepcional que confere a possibilidade de relativizar, por tempo determinado, a autonomia dos Estados, do Distrito Federal e dos Municípios. No Brasil, a intervenção tem como pilar o princípio da não intervenção, tendo o legislador constituinte fixado um rol exaustivo de condições materiais e formais para o processo interventivo nos artigos 34, 35 e 36 da Constituição, asseverando ainda em seu artigo 60, $\S 1 \stackrel{0}{ }$, que a vigência de intervenção federal é uma limitação circunstancial para emendar a Constituição.

Os Municípios, com o exercício prevalente do interesse local, dentre eles, a administração das cidades brasileiras, foram elevados a membros da Federação do Brasil no vigente ordenamento constitucional. Contudo, apesar da contribuição histórica para a formação do Estado brasileiro, ainda não alçaram uma efetiva materialização do seu papel no ordenamento democrático e de direito instaurado em 1988. A relativização da autonomia do município, com frequência interrompida pela nomeação de interventores, agente político desprovido de legitimidade popular, baseado em condições materiais ou formais não amparadas pela Constituição Federal, confirmam a fragilidade da tridimensionalidade da federação brasileira.

Desde a promulgação da vigente Constituição nenhuma intervenção federal foi decretada no Brasil. No entanto, em várias ocasiões, as autonomias municipais foram relativizadas em razão de decretação de intervenção estadual.

É nesse contexto de intervencionismo que este artigo analisa criticamente a possibilidade do Tribunal de Contas provocar a intervenção do Estado-membro em Município, em razão de atos de gestão praticados pelos agentes políticos, o que encontra previsão em alguns textos de Constituições Estaduais.

\section{O FEDERALISMO TRIDIMENSIONAL E A AUTONOMIA DO MUNICÍPIO}

O federalismo surgiu a partir da necessidade dos norte-americanos de estabelecerem um elo inquebrável para a Confederação de Estados vigente. Na Convenção da Filadélfia, reconheceram que o modelo confederativo não era suficiente para assegurar a unidade ou para afastar a possibilidade de secessão e adotaram a "federação" como uma forma de Estado nacional. O principal argumento em defesa da federação é que esta poderia assegurar uma forte união de 
caráter nacional, mas com capacidade para assegurar a auto-organização constitucional, legislativa, governamental e administrativa de cada Estado membro da federação a partir de uma repartição de competências por uma Carta constitucional escrita e rígida.

O processo de evolução do federalismo foi complexo. Inicialmente, o federalismo dual, inaugurado no período do Roger Taney como Chief Justice da Suprema Corte norte-americana, "acirrou a divisão entre os estados americanos. A divisão histórica do sul escravocrata e do norte industrializado recomeça a aflorar" (PINTO FILHO, 2002, p. 62-63). A atuação do governo federal com o objetivo de suprimir o tráfico de negros, iniciando um processo legislativo para instituir pesadas tarifas aduaneiras, gerou a separação de onze Estados e a instauração da guerra civil. Após vencer o Norte, a Suprema Corte, no caso Texas v. White (1869), consolidou o precedente "que sem os Estados em união não poderia haver um corpo político como os Estados Unidos", pois "a Constituição, em todas as suas disposições, cuida de uma União indestrutível, composta de Estados indestrutíveis".

No governo de Roosevelt (1933-1945), o modelo federativo norte-americano evoluiu a partir do julgamento do caso West Coast Hotel v. Parrish (1937) e do caso United States v. Darby. (1941). Para Rodrigues (1992, p. 196), o fato ocorreu a partir de uma nova vertente voltada a um "federalismo cooperativo", que passou a ser visto como conceito dinâmico e não estático, com as linhas divisórias das atividades da União e dos Estados identificadas como móveis e flexíveis, como garantia de preservação da essencial unidade federativa.

O ideal de um Estado federal ultrapassou continente e frutificou em outras nações, contudo, o federalismo não nasceu igual em todos os Estados nacionais que o adotaram. A característica histórica da construção do Estado caracterizou o tipo de federação que se assentou, bem como definiu os limites da descentralização e de sua defesa. A Alemanha (1815) e o México (1824) seguiram o exemplo dos estadunidenses. Na Suíça, dada a diversidade de povos, surgiu em 1848, a partir de uma Confederação flexível formada por regiões soberanas, para a defesa recíproca e assegurando a diversidade cultural $^{3}$. Na América do Sul, o primeiro país a adotar a federação como forma de Estado foi a Argentina em 1853, experimentando um salto econômico que influenciou o Brasil na instauração da República em $1889^{4}$.

\footnotetext{
${ }^{3}$ A Suíça atualmente é regida por uma "Constituição Federal da Confederação Suíça", vigente desde 1o de janeiro de 2000.

${ }^{4}$ A Constituição da Nação Argentina vigente foi sancionada em dezembro de 1994.
} 
Na sua origem, a federação decorreu de um processo de mitigação da soberania dos Estados-membros; entretanto, no Brasil, o processo de formação do Estado Federal ocorreu de forma inversa. A experiência da Suíça e do México já era conhecida dos brasileiros, mas foi o evidente sucesso dos argentinos e, "a despeito da admiração que nutriam pelo senso prático dos ingleses e do patriotismo francês, a grande referência político-institucional dos republicanos brasileiros eram mesmo os Estados Unidos" (LYNCH, 2012, p. 152). Rui Barbosa foi um profundo influente na importação da experiência norte-americana, tendo sido revisor do projeto do texto constitucional que viria a ser promulgado em 1891. Isso Ihe conferiu argumento de autoridade para, mais tarde, diante do excesso no uso da intervenção federal, conferir um legado de doutrina nacional de importância para o conhecimento do instituto que nasceu para assegurar o Estado federal.

O movimento contrário de formação da federação brasileira, isto é, sua origem centrífuga, decorrente da desagregação do Estado Unitário, diferente dos Estados Unidos que - como o próprio nome já informa - nasceu de uma federação centrípeta, aquela em que vários Estados soberanos efetivamente declinaram de sua soberania agregando em favor da União federal, não impediu que a federação brasileira tivesse vivenciado problemas comuns na história da formação das duas federações, como exemplo, a dualidade de governos e as discordâncias sobre a amplitude da autonomia dos membros da federação.

Uma característica fundamental da federação, provavelmente a mais marcante, é a descentralização política ${ }^{5}$ fixada numa rígida Constituição com a preservação da autonomia aos Estados formadores da União ${ }^{6}$. Significa que o Estado federal brota do consenso em declinar a soberania à União por objetivos comuns e gerais, assegurando a autonomia aos Estados-membros da federação para garantir as vontades específicas:

O princípio geral que norteia a repartição de competência entre as entidades componentes do Estado federal é o da predominância do interesse, segundo o qual à União caberão aquelas matérias e questões de predominante interesse geral, nacional, ao passo que aos Estados tocarão

\footnotetext{
${ }^{5}$ A repartição de competência é uma caraterística inaugural do Estado federal, todavia, não é exclusiva, pois já existem outras formas de Estados, inclusive Unitários e também Autonômicos, que adotam a descentralização como formas de organização do Estado, como exemplificam a Itália e a Espanha.

${ }^{6}$ Como lembra Lewandowski (1994, p. 15), "a multiplicidade de Federações que existem atualmente e a rica elaboração teórica sobre o assunto, é difícil precisar, posto que não há unanimidade, quais as características essenciais do Estado Federal, embora seja possível identificar no mínimo, quatro atributos básicos: (a) repartição de competência; (b) autonomia política das unidades federadas; (c) participação dos membros nas decisões da União; e (d) atribuição de renda própria às esferas de competência".
} 
as matérias e assuntos de predominante interesse regional, e aos Municípios concernem os assuntos de interesse local, tendo a Constituição vigente desprezado o velho conceito do peculiar interesse local que não lograra conceituação satisfatória em um século de vigência. (SILVA, 2011, p. 478)

Assim, é característica peculiar da vigente federação brasileira a tridimensionalidade que se configura na existência de três esferas federativas: a nacional, a regional e a local, respectivamente conferida à União, aos Estados e aos Municípios, para o exercício da competência segundo o interesse federativo em jogo ${ }^{7}$. Essa evolução conferiu às cidades brasileiras uma maior reponsabilidade na execução das políticas públicas, pois já não há um papel secundário e subordinado na atuação local, mas um configurado cenário que confere autonomia federativa aos municípios.

A Constituição de 1988 tornou o Município "ente federativo" dotado de autonomia política, legislativa, administrativa e financeira. Ademais, tornou o Município o ente responsável pela política urbana, num contexto marcado pela ampliação dos direitos sociais e pela execução descentralizada das políticas sociais, ampliando as atribuições dos governos municipais. (SANTOS, 2012, p. 827)

É na autonomia que encontramos o equilíbrio federativo, pois, como leciona Silva (2011, 484), para viabilizar que as relações entre a União, Estados, Distrito Federal e Municípios sejam harmoniosamente realizadas é necessário que haja um círculo preestabelecido de capacidades e de respeito aos princípios instituídos na Constituição Federal.

Destarte, para a garantia da preservação desse equilíbrio, um ente federado não pode se sobrepor ao outro, ainda que a teoria da prevalência de interesse possa aparentar uma sobreposição, esta não existe na federação. Nesta, a unidade é assegurada pelo inquebrantável pacto federativo e pela possibilidade de sua relativização por meio da intervenção contra o ente federado que descumprir as cláusulas estabelecidas constitucionalmente como de garantia do Estado federal.

\footnotetext{
${ }^{7}$ Ao Distrito Federal foram conferidas as competências do Estado e do Município, embora suas competências estejam mais próximas dos Estados federados.
} 


\section{A INTERVENÇÃO NO ENTE FEDERADO: O MODELO BRASILEIRO DE INTERVENÇÃO FEDERAL E ESTADUAL}

A Constituição tem um papel fundamental na instituição de um Estado federal e, como advertiu Kelsen (2003, p. 49), a elaboração de uma Constituição federal apresenta um problema técnico-jurídico de extrema relevância: a regulação da assim-chamada intervenção federal.

A intervenção no ente federado é um instrumento de garantia do Estado Federal, constituindo-se em um momento de excepcionalidade e temporalidade em que um ente político, membro da federação, poderá ter sua autonomia relativizada. Sua origem coincide com a inauguração do Estado Federal em 1787, tendo sido formalizado na Constituição dos Estados Unidos e, posteriormente, abarcada pelos novos Estados federais que surgiram. Estes foram influenciados pela capacidade demostrada pelo governo federal norte-americano de assegurar a unidade federal e impedir a resistência ao cumprimento de suas leis no conflito Whisky Insurrection que originou a primeira intervenção federal em 1784, adotada para conter a rebelião decorrente da cobrança de imposto sobre o uísque.

Na Alemanha, a possibilidade de intervir já constava na Ata Final do Congresso de Viena elaborada em 1815, preservada na Constituição de Weimar (1919) e no atual ordenamento constitucional de 1949. No ordenamento constitucional alemão, a intervenção do governo central nas unidades federadas recebe o nome de coerção federal (Bundeszwang) ou execução federal (Bundesexecution) $)^{8}$.

No México, em 1824, a Ata Constitutiva da Federação também obrigou a garantir a unidade por meio da intervenção, estando, atualmente, regida pela Constituição de 1917, que prevê o instrumento para preservação da unidade federativa, mas também institui a competência exclusiva ao Senado para intervir nomeando um governante provisório para o caso de desaparecimento de todos os poderes constitucionais de um Estado (desaparición de todos los poderes constitucionales de un Estado), capitulado no inciso $V$ do art. 76 da Constituição mexicana ${ }^{9}$.

\footnotetext{
${ }^{8}$ Estas não se confunde com a também existente Budesintervention, que se funda numa prestação de ajuda federal a um membro para restabelecer a normalidade quando ameaçado em sua ordem constitucional (ROVIRA, 1986, p. 213).

${ }^{9}$ Artículo 76. Son facultades exclusivas del Senado: [...] V. Declarar, cuando hayan desaparecido todos los poderes constitucionales de un Estado, que es llegado el caso de nombrarle un Gobernador provisional, quien convocará a elecciones conforme a las leyes constitucionales del mismo Estado. El nombramiento de Gobernador se hará por el Senado a propuesta en terna del Presidente de la República con aprobación de las
} 
Na Suíça, a intervenção federal foi assegurada na Constituição de 1848, tendo sido a primeira a usar o verbo 'intervir' e destacou-se pela inclusão da possibilidade de intervenção para garantir "a liberdade e os direitos dos cidadãos". Desde 10 de janeiro de 2000 é regida pela Constituição Federal da Confederação Suíça, que "repete o velho lema em que se calca o federalismo suíço que é o da seguridade do país, resguardando a coesão interna e da diversidade cultural" (PINTO FILHO, 2002, p. 36).

A Argentina espelhou-se no modelo estadunidense e, desde a instauração da federação, previu a intervenção como instrumento de garantia da unidade federal. No entanto, sob o argumento do restabelecimento da ordem pública gravemente perturbada, o governo federal argentino interveio em inúmeras províncias desvirtuando o original objetivo do instituto. A federação argentina, dada ao uso indiscriminado da intervenção federal para fins políticos e a necessidade de preencher os cargos com os apadrinhados do governo central, criou a figura do "interventor", agente até então desconhecido no federalismo norte-americano e europeu. A vigente Constituição da Nação Argentina, sancionada em dezembro de 1994, estabeleceu em seu capítulo exordial, que dispõe sobre "declarações, direitos e garantias", que "o governo federal poderá intervir em território das províncias para garantir a República, repelir invasões externas e para manter ou recuperar a ordem na província quando solicitadas"10.

$\mathrm{Na}$ história constitucional brasileira, a intervenção federal nasce com o primeiro ato constitutivo da República em 15 de novembro de 1889, que instituiu a federação dos "Estados Unidos do Brazil" e transformou as Províncias em Estados ${ }^{11}$. Assim, desde o dealbar da República, o processo interventivo foi efetivamente ${ }^{12}$ integrado ao cenário do recém-criado Estado Federal

dos terceras partes de los miembros presentes, y en los recesos, por la Comisión Permanente, conforme a las mismas reglas. El funcionario así nombrado, no podrá ser electo Gobernador constitucional en las elecciones que se verifiquen en virtud de la convocatoria que él expidiere. Esta disposición regirá siempre que las constituciones de los Estados no prevean el caso.

10 Artículo 60. El Gobierno federal interviene en el territorio de las provincias para garantir la forma republicana de gobierno, o repeler invasiones exteriores, y a requisición de sus autoridades constituidas para sostenerlas o restablecerlas, si hubiesen sido depuestas por la sedición, o por invasión de otra província.

${ }^{11}$ Decreto $n$ 으 1, de 15.11.1889. [...] Art. 6ㅇ. Em qualquer dos Estados, onde a ordem publica for perturbada e onde faltem ao governo local meios eficazes para reprimir as desordens e assegurar a paz e tranquilidade publicas, efetuará o Governo Provisório a intervenção necessária para, com o apoio da força publica, assegurar o livre exercício dos direitos dos cidadãos e a livre ação das autoridades constituídas.

12 A Constituição do Império (1824), em razão da descentralização da Administração e da concessão de autonomia às províncias, também previu a garantia do direito de intervir nos negócios das províncias nos artigos 71 e 72: "Art. 71. A Constituição reconhece, e garante o direito de intervir todo o Cidadão nos negócios da sua Província, e que são imediatamente relativos a seus interesses peculiares. Art. 72. Este direito será exercitado pelas Câmaras dos Distritos, e pelos Conselhos, que com o titulo de Conselho Geral da Província se devem estabelecer em cada Província, aonde não, estiver colocada a Capital do Império." 
brasileiro como forma de garantir sua integridade, vindo a primeira Constituição Republicana (1891) a assegurar que o "Governo Federal não poderá intervir nos negócios peculiares dos Estados".

Desde sua origem, com exceção da Constituição de 1937, a intervenção no Brasil fundouse no "Princípio da Não Intervenção". De forma contrária e afirmativa, as Constituições estadunidense, suíça, argentina e mexicana preservam o direito de intervir como regra.

A Constituição de 1891 manteve a abstração e generalização do modelo estadunidense e argentino. No entanto, em razão dos conflitos originados e acreditando que esse seria o motivo, na reforma de 1926 adotou-se um modelo substancialista e particularizado que foi espelhado nas Cartas constitutivas que se seguiram até a vigente Constituição de 1988. Contudo, o extensivo rol enunciativo das exceções ao princípio da não intervenção abriu novas possibilidades, vindo a estampar na história do Brasil várias fases de intervencionismo violador do pacto federal, já condenado desde o inaugural ordenamento constitucional republicano ${ }^{13}$.

Como já mencionado, há na atual federação brasileira características que a divergem das demais, tornando-a única como modelo federativo. Nas federações estrangeiras há um atributo comum que é a divisão da federação em apenas duas unidades federativas (União e Estados), caracterizando a necessidade de existir somente um modelo comum de intervenção: a "intervenção federal". No Brasil constituído em 1988, dada à tridimensionalidade da federação, que, além da União e dos Estados, elevou o Município a ente federativo, fez configurar um novo tipo para assegurar os valores constitucionais: a "intervenção estadual". Esta é uma espécie de intervenção indireta ou intervenção delegada, conferindo ao Estado a possibilidade de intervir no município localizado em seu território ${ }^{14}$. Ela não é dada ao Estado para somente proteger a sua integridade, mas, mais que isso, ela dada ao Estado para a proteção de todo o pacto federativo. 0 Estado, membro da federação, quando atua contra o município localizado em seu território, atua em nome do conjunto federativo, delegado pela Constituição Federal, porquanto, como leciona Kelsen (2003, p. 93), é "uma função regulada pela Constituição total, para sua defesa".

13 De 1930 até 1934 os Estados e os Municípios foram governados por interventores federais (regulamentado pelo Decreto no 20.348, de 29 de agosto de 1931). A Constituição de 1934 pretendeu revigorar o principio federativo, conferindo novos aspectos à intervenção federal que foram aprimorados pela Carta de 1946. Antes, porém, no interstício, a Constituição de 1937 ressuscitou o regime de "intervenção permanente" (PAULINO, 1983, p. 179) conferindo excessiva supremacia ao Governo Federal, reproduzido no período regime militar ditatorial que vigorou de 1964 até a promulgação da Constituição de 1988.

${ }^{14}$ A CRFB também possibilita que a União possa intervir em município localizado em Território, todavia, desde a Constituição de 1988 não há Território federal no Brasil. 
Deste modo, para adequar a particularidade do significado de intervenção na federação brasileira, já não mais limitado à intervenção federal, neste artigo atribuímos um significante que se adeque à tridimensionalidade federativa, passando a denominar o modelo interventivo brasileiro, como gênero, de "intervenção no ente federado", instando como espécies a intervenção federal e a estadual.

Outra característica da intervenção no ente federado no modelo brasileiro é que na Primeira República, a partir da reforma de 1926, o legislador nacional incluiu como condição formal a possibilidade do Poder Judiciário "requisitar" a intervenção federal. Mantida na vigente ordem constitucional, haverá requisição do STF para garantir o livre exercício dos Poderes nas unidades da Federação, quando o Poder coacto ou impedido for o Judiciário (art. 34, IV, CRFB) e para assegurar a execução de ordem ou decisão judicial (art. 34, VI, parte final c/c art. 36, II, CRFB), conferindo esta última também ao Tribunal de Justiça quando a intervenção for contra o Município (art. 35, parte final, c/c art. 36, II, CRFB).

A intervenção no ente federado destina-se, tradicionalmente e em regra, para garantir a manutenção da forma republicana, para proteger de invasão externa e para auxiliar a ordem nas rebeliões internas. No Brasil, a Carta de Outubro de 1988 fundou o Estado Federal sobre o pilar do Princípio da Não Intervenção, proibindo emendar a constituição na vigência de intervenção federal e fixando um rol exaustivo em que a União possa intervir nos Estados e no Distrito Federal (art. 34), bem como nos Municípios localizados em Território Federal (art. 35), enquanto os Estados poderão intervir nos Municípios localizados em seus territórios (art. 35).

É neste contexto que a intervenção como "antítese da autonomia" (SILVA, 2011, p. 485) constitui uma medida excepcional que só pode ocorrer nas hipóteses exaustivamente descritas na Constituição de 1988, pois, ainda que temporariamente, afasta a autonomia dos entes federados. Caracteriza por ser ato político; político no aspecto de que se encontra no domínio da discricionariedade do Chefe do Poder Executivo e do controle do Poder Legislativo, mas sob o âmbito de apreciação pelo Poder Judiciário sob o manto da juridicidade.

Nos art. 34 e 35 da Constituição Federal são elencados os pressupostos materiais para a decretação de intervenção, sendo eles, para a defesa da integridade nacional, repelir invasão estrangeira ou de uma unidade da Federação em outra, pôr termo a grave comprometimento da ordem pública, garantir o livre exercício de qualquer dos Poderes nas unidades da Federação, reorganizar as finanças da unidade da Federação, prover a execução de lei, ordem ou decisão judicial e assegurar a observância dos princípios constitucionais da forma republicana, do sistema 
representativo e do regime democrático; dos direitos da pessoa humana; da autonomia municipal; da prestação de contas e da aplicação do mínimo exigido da receita pública na manutenção e desenvolvimento do ensino e nas ações e serviços públicos de saúde.

São fundamentos que objetivam defender a unidade federativa e os valores constitucionais expressamente definidos na Constituição. No Brasil, a intervenção no ente federado é uma medida de exceção de natureza política empreendida pela União ou pelo Estado-federado, através de seus poderes constituídos, que interfere coercitivamente e temporariamente nos assuntos internos do Estado ou do Município.

\section{A CIDADE INTERROMPIDA: UM NOVO CAPÍTULO DO INTERVENCIONISMO BRASILEIRO PROVOCADO PELO TRIBUNAL DE CONTAS}

No Brasil, como na Argentina e no México, há uma histórica analogia da intervenção como "instrumento de submissão dos poderes locais ao governo central" (LEWANDOWSKI,1993, p. 125). Na década varganiana, o Brasil instituiu regras destinadas a regulamentar a intervenção ${ }^{15}$ e as adotou como instrumento de manutenção da exagerada prevalência do governo central sobre o local. Eram tantas as intervenções que a normalidade era que os Estados e os Municípios - estes nem mesmo eram entes federados - fossem geridos por interventores. Loureiro (1974 p. 39), analisando a possibilidade de impeachmet para afastar os interventores, ainda sob a égide da Constituição de 1967, contemplou a intervenção como uma "doença infantil do federalismo" brasileiro. Essa compreensão decorre do fato de que a intervenção no ente federado e, em especial, a nomeação de um interventor, afeta um instrumento democrático posto à disposição da sociedade: o voto.

Até o nascer das discussões sobre a necessidade de o povo participar das decisões do Estado, a representação política, pelo exercício do voto, foi considerada como a única forma de participação suficiente para a realização da democracia (GALANTE, 2004, p. 16). O voto é a síntese da democracia. Como advertiu Pedra (2012, p. 159), “a democracia está vinculada ao princípio da soberania popular. E o fracasso da democracia representativa demonstra de certa forma o insucesso de toda a teoria da soberania popular ou da legitimidade do poder que nela se assenta".

É certo que, mesmo mitigando a legitimidade popular, haverá circunstância em que a intervenção será o único meio para estabelecer a ordem constitucional, haja vista que balizar o

15 Em 1931, o "Código dos Interventores" (Decreto no 20.348, de 29/8/1931) e em 1939 (Decreto no 1.202, de 8.4.1939). 
Estado federal e a democracia, assegurando a estabilidade, para, como efeito, afiançar a dignidade do indivíduo, também é um substrato da intervenção no ente federal. Contudo, o instituto da intervenção no ente federado somente pode ser executado nas condições materiais e formais previamente estabelecidas na Constituição Federal, uma vez que, como advertiu Ernesto Leme (1926, p. 152), "a intervenção é como certos medicamentos que requerem muito cuidado na sua aplicação: drogas que salvam, em certas doses, são venenos perigosíssimos quando deles abusam".

Desde a promulgação da Constituição em 1988, não ocorreu nenhuma requisição, declaração ou execução do ato coercitivo da espécie "intervenção federal", isto é, nenhum Estado ou o Distrito Federal sofreu intervenção em sua autonomia federal. As solicitações ao Poder Executivo ou mesmo as representações interventivas pelo Procurador Geral da República junto ao Supremo Tribunal Federal não obtiveram êxito.

A despeito de nenhuma intervenção federal ter sido decretada ou mesmo ter obtido a procedência por parte do Supremo Tribunal Federal, este teve a oportunidade de apreciar representações interventivas propostas pelo Procurador Geral da República. Algumas pretensões alcançaram grande mídia nacional e entraram para a história do direito constitucional brasileiro. A primeira (IF 114/MT) foi proposta em razão da gravidade dos fatos contra a dignidade da pessoa humana com o linchamento de três pessoas (queimadas vivas) na alcunhada "Chacina de Matupá", decorrente de um Estado federado que, por meses, não pagava as remunerações dos servidores públicos e a Polícia se encontrava desprovida de bens materiais indispensáveis para a prestação de serviços à coletividade; a segunda (IF 5.179/DF) originou da atuação da Polícia Federal deflagrada em novembro de 2009, batizada de "Operação Caixa de Pandora", no qual expunha o envolvimento de agentes políticos em atos de corrupção na administração do Distrito Federal.

Em ambos os julgamentos, o Supremo Tribunal Federal primou pela proteção do princípio federativo e assegurou a autonomia dos Estados federados, sob o argumento de que a ordem constitucional já estava instaurada.

No mesmo sentido, ainda que diante de um elevado número de pretensões interventivas fundadas no descumprimento de ordem judicial por não pagamento de precatórios, o Supremo Tribunal Federal não se afastou do precedente da prevalência da autonomia dos entes federados, ficando o entendimento de que a ausência de configuração de atuação dolosa e deliberada do Estado com finalidade de não pagamento desnatura a presença das condições para a pretensão 
interventiva ${ }^{16}$. O vencedor voto divergente trouxe como fundamento a lavra do Ministro Nelson Hungria, proferido no IF 20 (publicado em 15.07.1954) ${ }^{17}$, segundo o qual, para justificar a intervenção, não basta a demora de pagamento, na execução da ordem ou decisão judiciária, por falta de numerário; é necessário o intencional ou arbitrário embaraço ou impedimento oposto a essa exceção", sob a máxima de que "onde não há, até rei perde".

No Supremo Tribunal Federal há o registro de que de 1991 a 2015 foram autuados 5.024 pretensões de intervenção federal, tendo sido julgadas 6.244 (neste total estão incluídas as autuadas antes de 1988), reafirmando a Corte Suprema a natureza excepcional da intervenção, conferindo primazia à estabilidade constitucional ao assegurar a prevalência do princípio federativo e da autonomia dos Estados federados.

Contudo, na esfera estadual, o precedente não se repete. Os Tribunais de Justiça, com algumas exceções, têm riscado o instituto da intervenção estadual, possibilitando um intervencionismo semelhante aos tempos passados da história brasileira, fazendo surgir uma nuvem cinzenta sobre o federalismo brasileiro. Essa atuação decorre do fato de que, mesmo diante de um novo pacto federativo tridimensional, o tema da autonomia dos municípios não é pacífico, como rememora José Luiz Quadros de Magalhães (2004, p. 197):

A partir da Constituição de 1988, os municípios brasileiros não só mantêm sua autonomia, como conquistam a posição de ente federado, podendo, portanto, elaborar suas Constituições municipais (chamadas pela Constituição Federal de leis orgânicas), auto-organizando os seus poderes executivos e Legislativo e promulgando sua Constituição sem que seja possível ou permitida a intervenção do Legislativo estadual ou federal para a respectiva aprovação. [...] Alguns autores têm rejeitado a ideia do município como ente federado (que caracteriza o federalismo de três níveis criado pela Constituição de 1988), por ser uma ideia nova, mas seus argumentos (ausência de representação no Senado, impossibilidade de falar-se em União histórica de municípios, ausência de poder judiciário no município) são frágeis ou inconsistentes diante da característica essencial do federalismo, que difere esta forma de Estado de outras formas

16 INTERVENÇÃO FEDERAL. 2. Precatórios judiciais. 3. Não configuração de atuação dolosa e deliberada do Estado de São Paulo com finalidade de não pagamento. 4. Estado sujeito a quadro de múltiplas obrigações de idêntica hierarquia. Necessidade de garantir eficácia a outras normas constitucionais, como, por exemplo, a continuidade de prestação de serviços públicos. 5. A intervenção, como medida extrema, deve atender à máxima da proporcionalidade. 6. Adoção da chamada relação de precedência condicionada entre princípios constitucionais concorrentes. 7. Pedido de intervenção indeferido. (IF 2915, Relator(a): Min. MARCO AURÉLIO, Relator(a) p/ Acórdão: Min. GILMAR MENDES, Tribunal Pleno, julgado em 03/02/2003, DJ 28-112003 PP-00011 EMENT VOL-02134-01 PP-00152)

${ }^{17}$ STF - IF-20/MG - Rel. Min. Nelson Hungria - Pleno - DJ. de 15.7.54, pág. 9336 - Ement. vol. 177-01/167. 
descentralizadas, ou seja, a existência de um poder constituinte decorrente ou de competências legislativas constitucionais nos entes federados.

Neste contexto, o legislador constituinte originário expressamente assegurou a proteção da autonomia do município no artigo 34 da Constituição Federal, prescrevendo que sua violação é pressuposto para a declaração de intervenção federal.

Analisando os julgamentos do Supremo Tribunal Federal em âmbito recursal e dos Tribunais de Justiça foi constatado que, quando se trata de intervenção estadual contra os municípios localizados no território dos Estados federados, os Tribunais de Justiça não estão primando pela mesma segurança jurídica resguardada pela Corte Suprema. O fato também recebe a negativa contribuição de algumas Constituições Estaduais. Constata-se que 22 textos constitutivos originários dos Estados federados modificaram as condições materiais ou formais para o processo de intervenção estadual previsto nos artigos 35 e 36 da Constituição Federal. Os Estados do Acre, Paraíba, Pernambuco, Rio de Janeiro, Rio Grande do Sul, Rondônia e Sergipe previram outras condições materiais e, junto com os Estados de Alagoas, Amapá, Amazonas, Bahia, Ceará, Espírito Santo, Goiás, Maranhão, Mato Grosso, Mato Grosso do Sul, Pará, Paraná, Piauí, Santa Catarina e Tocantins, ampliaram o rol de competentes para instaurar o processo de intervenção estadual.

Esse ambiente emanado das leis constitutivas dos Estados federados frutificou, em alguns, o uso inescrupuloso da intervenção estadual contra os municípios localizados em seu território. Mesmo após algumas constituições estaduais terem seus dispositivos declarados inconstitucionais pelo STF ${ }^{18}$, o ambiente instituído pelo texto originário da Constituição Estadual permanece. Atualmente, em alguns Estados federados, como Maranhão e Pernambuco, o Tribunal de Contas atua por meio do Ministério Público, ainda que na ADI 614/MA, julgada em 1992, o Supremo Tribunal Federal tenha proferido acórdão reafirmando que é do Poder Legislativo a competência para apreciar o requerimento interventivo do Tribunal de Contas:

[...] A tomada de contas do Prefeito Municipal, objeto principal do controle externo, é exercido pela Câmara Municipal com o auxílio do Tribunal de Contas, órgão a que cumpre emitir parecer prévio, no qual serão apontadas eventuais irregularidades encontradas e indicadas as providências de ordem corretiva consideradas aplicáveis ao caso pela referida casa legislativa, entre as quais a intervenção. Tratando-se, nessa última hipótese, de medida que implica séria interferência na autonomia municipal e grave restrição ao exercício do mandato do Prefeito, não pode ser aplicada sem rigorosa

${ }_{18}$ ADI 614/MA em 1992, ADI 1000/CE em 1994, ADI 2631/PA em 2002 e, no controle difuso, no SS 1361/PE em 1994 e SS 1606/PA em 2000. 
observância do princípio do due process of law, razão pela qual o parecer opinativo do Tribunal de Contas será precedido de interpelação do Prefeito, cabendo à Câmara de Vereadores apreciá-lo e, se for o caso, representar ao Governador do Estado pela efetivação da medida interventiva. Relevância da questão, concorrendo o pressuposto da conveniência da medida requerida. Cautelar deferida, para suspensão da eficácia dos dispositivos impugnados ${ }^{19}$.

Em 1996, o Governador da Paraíba, alicerçado em denúncia de improbidade administrativa e solicitação do Tribunal de Contas (competência descrita no § 40 do artigo 15 da Constituição Estadual $)^{20}$, decretou a intervenção em um Município da Paraíba.

Em 1999, o STF apreciou o pedido de Suspensão de Segurança SS 1.361/PE originado do Estado do Pernambuco em intervenção estadual. O litígio proveio da originalidade da Constituição daquele Estado ao estabelecer um leque extensivo de princípios ${ }^{21}$ a serem preservados por meio da intervenção estadual além de ter conferido ao Tribunal de Contas a competência para solicitar. Ao apreciar o pedido monocraticamente, o Presidente do STF, Ministro Carlos Velloso, registrou que o Município já havia sofrido "cinco intervenções nos últimos trinta anos" e decidiu com fundamento na inconstitucionalidade da solicitação pelo Tribunal de Contas.

No mesmo ano, o STF assegurou a um Município do Pará o retorno ao cargo do Prefeito, após decretação de intervenção pelo Governador, referendada pela Assembleia Legislativa, mas

\footnotetext{
${ }^{19}$ ADI 614 MC, Relator(a): Min. ILMAR GALVÃO, Tribunal Pleno, julgado em 14/10/1992, DJ 18-05-2001 PP00062 EMENT VOL-02030-01 PP-00056.

${ }^{20}$ Dispõe o § 40 do Art. 15, com a redação dada pela Emenda Constitucional no 5, de 24 de novembro de 1994: “[...] \& 40 Poderá ainda ser iniciado processo de intervenção em Município, mediante solicitação da Câmara Municipal aprovada pelo voto da maioria absoluta de seus membros, ou do Tribunal de Contas dos Municípios ao Governador, que procederá na forma estabelecida no $\S 1$ 1 deste artigo".

${ }^{21}$ É interessante registrar o dispositivo constitucional do Estado de Pernambuco, pois ele é descritivo, diferente da maioria dos demais textos estaduais constitutivos. "Art. 91. O Estado não intervirá em seus Municípios, exceto quando: [...] IV - o Tribunal de Justiça der provimento à representação para assegurar a execução de lei ou ato normativo, de ordem ou de decisão judicial, bem como a observância dos seguintes princípios: a) forma republicana, representativa e democrática; b) direitos fundamentais da pessoa humana; c) autonomia municipal; d) prestação de contas da administração pública, direta, indireta ou fundacional; e) o livre exercício, a independência e a harmonia entre o Executivo e o Legislativo; f) forma de investidura nos cargos eletivos; g) respeito às regras de proibições de incompatibilidades e perda de mandato, fixadas para o exercício dos cargos de Prefeito, Vice-Prefeito e Vereador; h) obediência à disciplina constitucional legal de remuneração de cargos públicos, inclusive eletivos e políticos; i) proibição do subvencionamento de viagens de Vereadores, exceto no desempenho de missão autorizada, representando a Câmara Municipal; j) proibição de realização de mais de uma reunião remunerada da Câmara Municipal, por dia; I) mandato de dois anos dos membros da Mesa da Câmara Municipal, vedada a recondução para o mesmo cargo na eleição imediatamente subseqüente; $m$ ) submissão às normas constitucionais e legais de elaboração e execução das leis do plano plurianual, das diretrizes orçamentárias anuais e do orçamento, bem como de fiscalização financeira, contábil e orçamentária; n) conformidade com os critérios constitucionais e legais para emissão de títulos da dívida pública; o) adoção de medidas ou execução de planos econômicos ou financeiros com as diretrizes estabelecidas em lei complementar estadual; p) cumprimento das regras constitucionais e legais relativas a pessoal; q) obediência à legislação federal ou estadual".
} 
solicitada diretamente pelo Tribunal de Contas após relatório técnico de inspeção em que afirma ter encontrado irregularidades praticadas pelo agente político ${ }^{22}$.

Em janeiro de 2004, o Ministro Presidente do Superior Tribunal de Justiça (quando ainda detinha o STJ competência constitucional), em apreciação monocrática no MC 7642/GO, restaurou a ordem democrática em um município do Estado de Goiás, após 17 meses de intervenção estadual originada de solicitação do Tribunal de Contas por irregularidade em um balancete (abril/2001).

No âmbito dos Tribunais de Justiça, encontramos órgãos que seguem a mesma linha da Suprema Corte; entretanto, há um elevado número de representações interventivas em que a atuação é ordinária e sem caráter de excepcionalidade, constituindo-se a intervenção estadual em um instrumento de manutenção do poder político.

A competência para "representação" por intervenção no ente federado é do ProcuradorGeral da República para a intervenção federal (artigo 36, III, CRFB). Ademais, a Constituição Federal, no inciso IV do artigo 129, confere como função institucional do Ministério Público promover a "representação para fins de intervenção da União e dos Estados". Entretanto, ao tratar da intervenção estadual, o legislador constituinte deixou uma abertura hermenêutica que permite, de certa forma, compreender que a iniciativa da "representação para assegurar a observância de princípios indicados na Constituição Estadual" (artigo 35, IV, CRFB) não está necessariamente vinculada às funções ministeriais, podendo ser exercida por outro interessado. Dissentindo desta abertura interpretativa, o STF afastou a legitimidade de Partido Político, de Parlamentar Federal ${ }^{23} \mathrm{e}$ de Tribunal de Contas $^{24}$ proporem representação interventiva em desfavor de Município.

Seguindo os precedentes do STF, José Afonso da Silva (2011, p. 490) reafirma que "a representação ao Tribunal de Justiça, como peça inicial da ação interventiva no Município, cabe ao Procurador Geral de Justiça competente para conhecer da representação", nos mesmos moldes fixados no art. 36, inciso III, da CRFB, para a intervenção federal.

Tendo em consideração tal precedente, merece uma análise mais detida a intervenção estadual em Município do Estado de Pernambuco. A decisão analisada foi liminarmente concedida em novembro de 2015 pelo Tribunal de Justiça do Estado de Pernambuco após representação

22 SS 1606, Relator(a): Min. CARLOS VELLOSO, julgado em 20/12/1999, publicado em DJ 01/02/2000 PP00104

23 IF 102, Relator(a): Min. NÉRI DA SILVEIRA, Tribunal Pleno, julgado em 13/03/1991, DJ 13-03-1992 PP02921 EMENT VOL-01653-01 PP-00001.

${ }^{24}$ ADI 614 MC, Relator(a): Min. ILMAR GALVÃO, Tribunal Pleno, julgado em 14/10/1992, DJ 18-05-2001 PP00062 EMENT VOL-02030-01 PP-00056. 
interventiva do Ministério Público. Relevante lembrar - como esclarecido anteriormente - que no Estado de Pernambuco há previsão em seu texto constitucional que confere ao Tribunal de Contas a possibilidade de solicitar intervenção, gerando uma tradição de este órgão participar ativa e diretamente da suspensão da autonomia municipal. Após o julgamento do STF (SS 1.361/PE), de que o Tribunal de Contas é auxiliar do Poder Legislativo e que compete a este a iniciativa interventiva, percebe-se que a dinâmica mudou e que com os mesmos fundamentos, a intervenção em município é instaurada a partir de solicitação do Tribunal de Contas ao Ministério Público. Nada a opor, não fossem os motivos que justificam a intervenção. Para o estudo destaca-se o julgamento da Intervenção Estadual em que figuram como "réus" o Município de Gravatá-PE e, também, o Prefeito Municipal.

Sustenta o Ministério Público a violação aos princípios descritos na Constituição Estadual do Estado de Pernambuco, destacando as alíneas " $m$ ", " $p$ " e " $q$ " do inciso IV do artigo 91, quais sejam:

Art. 91. O Estado não intervirá em seus Municípios, exceto quando: [...]

IV. O Tribunal de Justiça der provimento à representação para assegurar a execução de lei ou ato normativo, de ordem ou de decisão judicial, bem como a observância dos seguintes princípios: [...]

m. Submissão às normas constitucionais e legais de elaboração e execução das leis do plano plurianual, das diretrizes orçamentárias anuais e do orçamento, bem como de fiscalização financeira, contábil e orçamentária; [...]

p. Cumprimento das regras constitucionais e legais relativas a pessoal;

q. Obediência à legislação federal ou estadual;

Todos os princípios elencados pelo Ministério Público não se coadunam com os descritos nos artigos 34 ou 35 da Constituição Federal, bem como o fundamento da peça inicial são fatos imputados ao Prefeito Municipal, o que, inclusive, o torna "réu" na representação interventiva. Em suma, os fatos imputados ao Prefeito pelo Ministério Público como motivadores da intervenção são "fraudes em licitação, superfaturamento de contratos, despesas com pessoal não autorizadas em lei e irregularidades no regime de previdência própria", estando transcrito no relatório apresentado pelo Desembargador Relator, o qual sintetiza o seu fundamento na impossibilidade de manter o agente político no cargo em face dos desvios e enriquecimento ilícito:

[...] Justifica o seu pedido ao fundamento de que "foram verificados pelo Tribunal de Contas do Estado de Pernambuco diversos atos praticados pelo Prefeito, [...], os quais apontam no sentido de aplicação normativa da intervenção do Estado" (fls. 24), de modo que "a permanência do Prefeito de Gravatá, [...], à frente da gestão do Município significa a manutenção e 
continuidade de uma administração eivada de desvios e locupletamento pessoal de verbas públicas" (fls. 25) ${ }^{25}$.

O uso irregular da intervenção estadual é retratado na conclusão do voto quando nem mesmo menciona o tema "intervenção estadual", mas converte o objeto da pretensão interventiva em afastamento do Prefeito:

Diante doe exposto, voto para CONCEDER a medida cautelar requerida pelo Ministério Público do Estado de Pernambuco, com fulcro no art. 5o da Lei no 12.562/2011 c/c art. 145-A do RITJPE, para afastar, provisoriamente, o Prefeito Municipal [...] da administração direta do Município de Gravatá/PE devendo ser comunicado, de imediato, ao Governador do Estado para proceder com a execução da medida, observado o procedimento legal. (TJ/PE, IE no 0408355-0, julg. 16.11.2015)

Há nos autos um pedido do Vice-Prefeito para assumir a gestão, mas que, no julgamento, foi descartado sob o argumento de que somente seria possível "quando comprovado a prática de ilícitos penais ou civis, ou em caso de cassação pela Câmara de Vereadores, medidas que possuem natureza punitiva aplicáveis unicamente ao Prefeito". O decreto interventivo foi expedido em novembro de $2015^{26}$, estabelecendo o prazo da intervenção até 31 de dezembro de 2016, tendo sido nomeado interventor um coronel da Polícia Militar, como já ocorreu em outras intervenções naquele Estado.

O que se constata na pesquisa é que o julgamento adotado pelo Poder Judiciário de Pernambuco não é único, como também ocorre em outros Estados federados. O estudo mostra que não há segurança jurídica na relação federativa do Estado brasileiro no que se refere à preservação da autonomia política dos Municípios, a julgar que não são observados os pressupostos materiais e formais descritos no texto da Constituição Federal, aquela que é efetivamente a única constitutiva da federação brasileira, como leciona Kelsen (2003, p. 60): a "Constituição total", isto é, a Carta política que totaliza os fundamentos do Estado Federal.

Pode-se dizer que a autonomia dos entes federados brasileiros é um edifício em construção. Não nasceu pronta, foi erigida durante a evolução histórica do constitucionalismo nacional, espelhando-se em outras experiências, mas tendo suas bases construídas em novos alicerces, a partir de um federalismo centrífugo e tridimensional. O princípio da não intervenção mantém-se como o alicerce da Federação brasileira e, como advertiu Rui Barbosa (1975, p. 23), "todo o poder se encerra um dever: o dever de não se exercitar o poder, senão dadas as

${ }^{25} \mathrm{TJ} / \mathrm{PE}$, IE no 0408355-0, julg. 16.11.2015.

${ }^{26}$ Decreto no 42.387, de 17 de novembro de 2015. 
condições, que legitimem o seu uso, mas não deixar de o exercer, dadas as condições que o exijam".

As Constituições Estaduais não podem instituir condições materiais ou formais não previstas na Constituição Federal, consoante precedido na ADI 614/MA (1992), do qual também foi destacado que, se assim fosse, haveria na federação brasileira "vários regimes de intervenção conforme a Carta Magna de cada Estado".

Neste mesmo sentido, em 1993, ao apreciar o pedido liminar na ADI 558/RJ, o Supremo Tribunal Federal julgou pela suspensão da eficácia do dispositivo da Constituição do Estado do Rio de Janeiro que reduzia o pressuposto material previsto na CRFB, aderindo ao fundamento de que o dispositivo "é incompatível com o art. 35 da Constituição Federal, pois estabelece condição, reduzindo drasticamente o alcance da norma constitucional federal".

A Constituição do Estado do Ceará também teve a suspensão da eficácia do dispositivo constitucional que autorizava a participação do Tribunal de Contas no processo de intervenção ${ }^{27}$. De igual forma, o Supremo Tribunal Federal, na ADI 2631/PA, julgada em 2003, originada do Estado do Pará, afastou a eficácia de semelhante dispositivo, reafirmando que o ato político da intervenção é ato patológico, excepcional, e por ser atentatório à autonomia municipal, há de estar expressamente previsto na Constituição Federal.

Para Kelsen (2003, p. 49), a regulamentação da intervenção federal é um problema técnico jurídico de toda Constituição elaborada sob a concepção de um Estado Federal, e que, sendo "influenciada pelo discurso de proteção da essência do pacto federativo", faz surgir a "possibilidade de que as Constituições dos Estados federativos, na resolução daquele problema, tomem caminhos bastante diversos". O modelo federativo brasileiro não é abstrato ou ideal, mas sim definido pela própria Constituição da República. Se a Constituição Federal - a Constituição

\footnotetext{
${ }^{27}$ Contudo, haja vista que havia uma alteração por emenda constitucional ao texto antes da propositura da ação, ainda que não tivesse extraído o vício, no mérito, a ação não foi conhecida. "EMENTA: Ação direta de inconstitucionalidade. $\S 1$ O do artigo 40 da Constituição do Estado do Ceará em sua redação original. Questão de ordem. - No caso, tendo em vista que já quando da propositura da presente ação, em 28.01.1994, o parágrafo primeiro do artigo 40 da Constituição do Estado do Ceará, em sua redação original, que foi o texto atacado, já tinha sido alterado pela Emenda Constitucional no 9, de 16.12.92, essa alteração, por ser anterior e não posterior a tal propositura, não dá margem a tornar-se prejudicada esta ação, mas sim ao reconhecimento de que ela não pode ser conhecida, por se ter firmado a jurisprudência desta Corte no sentido de que não cabe ação direta de inconstitucionalidade que tenha por objeto norma já ab-rogada ou derrogada, independentemente de ter, ou não, produzido efeitos concretos. Questão de ordem que se resolve no sentido de não se conhecer desta ação direta, cassando-se a liminar deferida." (ADI 1000 QO, Relator(a): Min. MOREIRA ALVES, Tribunal Pleno, julgado em 05/06/2002, DJ 09-08-2002 PP-00067 EMENT VOL-02077-01 PP-00014 RTJ VOL-00185-03 PP-00781)
} 
totalizadora da federação - estabeleceu as condições nas quais podem ocorrer a intervenção, seja a federal seja a estadual, trata-se um "dever ser" único em toda a federação.

O reconhecimento da autonomia dos municípios brasileiros é de fundamental importância para a concretização do modelo federativo tridimensional e a preservação do sistema representativo, mas, para esta evolução, o instituto da intervenção não pode ser utilizado como instrumento de correção ou punição do agente político. Utilizar a intervenção para o que ela não se presta, como já ressaltou Rui Barbosa $(1975$, p. 95) ainda sob a égide da Primeira República, faz dela "o sistema da mais iníqua e nefanda tirania, que jamais se imaginou, para aniquilar o civismo das populações resistentes ao domínio dos seus carrascos".

A possibilidade de que o pacto federativo seja mantido com políticas públicas mais eficientes depende de que sejam logrados avanços na maior cooperação federativa (SANTOS, 2012, p. 847) e que sejam respeitadas as autonomias municipais. A defesa do pacto federativo está adstrita aos entes federados que compõem este pacto. O Tribunal de Contas é órgão administrativo auxiliar do Poder Legislativo, e não detém competência constitucional para o controle político direto sobre o ente federado, mas sim o controle dos atos de gestão dos agentes públicos, cabendo-Ihe, nos limites do inciso XI do artigo 71 da Constituição Federal, "representar ao Poder competente sobre irregularidades ou abusos apurados" pelos gestores públicos.

\section{CONCLUSÃO}

Sintonizado com a história dos Municípios brasileiros desde a instauração da Primeira República e com o seu papel na edificação da federação, o legislador constituinte originário de 1988 elevou o Município a ente membro da federação brasileira, assegurando sua autonomia política e instituindo um novo modelo de federação tridimensional. Para preservação dessa característica, e objetivando instituir cláusulas que assegurassem o pacto federativo, também previu a intervenção no ente federado mediante a presença das condições materiais e formas descritas nos artigos 34, 35 e 36 da CRFB.

Como visto, a intervenção no ente federado é um ônus a ser suportado pelos membros da federação e também pelo cidadão integrante da sociedade, para garantia da existência do próprio Estado federal e dos valores constitucionais que assegura. No entanto, a cláusula de garantia exaustivamente descrita nos artigos 34 e 35 da CRFB não tem sido suficiente para assegurar a estabilidade da Federação brasileira, mostrando uma face oculta das intervenções em alguns 
Estados federados que se assemelham aos tempos do intervencionismo vivenciados na história nacional anterior ao vigente ordenamento constitucional.

O Tribunal de Contas é um órgão de relevante importância para o controle da gestão pública e, após a Constituição de 1988, somada à organização do Ministério Público de Contas, tem adotado um papel mais célere e responsável no exercício de sua atribuição. Todavia, apesar de algumas Constituições de Estados-membros conferirem ao Tribunal de Contas o poder de solicitar a intervenção estadual, este não integra os órgãos e autoridades relacionados para a defesa do pacto federativo.

Assim, a mitigação da autonomia de Municípios com base neste fundamento, isto é, na adoção pelos Estados de condições materiais e formais diferentes da Constituição Federal, conferindo ao Tribunal de Contas atribuição para provocar a intervenção em razão de irregularidades cometidas pelo agente político, bem como a influência do modelo constitucional anterior (1969) - significado no caso estudado com a nomeação de militar para a função de interventor e o largo período de intervenção (13 meses) -, tem configurado o desvio de finalidade de um instrumento valioso para a federação.

Para a própria garantia da Federação brasileira, os atos que justificam a intervenção no ente federado (exaustivamente previstos nos artigos 34 e 35 da CRFB) não podem ser confundidos com as ações ilegítimas cometidas pelo agente político (que possuem meios próprios de correção), pois, agindo com base em condições materiais e formais não previstas no texto da Constituição Federal, o Estado federado viola os limites constitucionais estabelecidos para a intervenção no Município, fazendo emergir um ato coercitivo punível até mesmo com a intervenção federal, desta feita contra o próprio Estado-membro interventor.

\section{REFERÊNCIAS}

GALANTE, Elisa Helena Lesqueves. Participação popular no processo legislativo. Revista da Faculade de Direito de Campos, Ano VII, n. 4 e n. 5, 2004, p. 435-483

JACQUES, Paulino. Curso de Direito Constitucional. 9. ed. Rio de Janeiro: Forense, 1983.

KELSEN, Hans. Jurisdição constitucional. São Paulo: Martins Fontes, 2003.

LEME, Ernesto. A intervenção federal nos Estados. 2. ed. São Paulo: Revista dos Tribunais, 1926. 
LEWANDOWSKI, Enrique Ricardo. LEWANDOWSKI, Enrique Ricado. A intervenção Federal no Brasil e no México. Universidad Nacional Autônoma do México, 1993: p. 95-127. (disponível em: http://biblio.juridicas.unam.mx/libros/7/3447/7.pdf)

Pressupostos materiais e formais da intervenção federal no Brasil. São Paulo: Revista dos Tribunais, 1994.

LYNCH, Christian Edward Cyril. O caminho para Washington passa por Buenos Aires. A recepção do conceito argentino do estado de sítio e seu papel na construção da República brasileira (18901898). Revista Brasileira de Ciências Sociais: São Paulo, vol. 27, n 78, p. 149-196, fevereiro /2012.

LOUREIRO, José Sansão. O "impeachment" dos executivos nomeados no direito constitucional brasileiro. Revista da Faculdade de Direito UFPR, v. 17, n. 0 (1974), p. 39-42.

MAGALHÃES, José Luiz Quadros de. O resgate da democracia representativa através da democracia participativa. Revista da Faculdade de Direito da Universidade Federal de Minas Gerais, Belo Hrizonte, no 44, Jan-Jun/2004, p. 181-216.

NABAIS, José Casalta. Por uma liberdade com responsabilidade. Coimbra: Coimbra, 2007.

PEDRA, Adriano. A Constituição viva: poder constituinte permanente e cláusulas pétreas na democracia participativa. 2. ed. Rio de Janeiro: Lumen Juris, 2012.

PINTO FILHO, Francisco Bilac Moreira. A intervenção federal e o federalismo brasileiro. Rio de Janeiro: Forense, 2002.

RODRIGUES, Leda Boechat. A Corte Suprema Americana e o direito constitucional americano. Rio de Janeiro: Civilização Brasileira, 1992.

ROVIRA, Enoch Alberti. Federalismo y Cooperación em la República Federal Alemana. Madri: Centro de Estudos Constitucionales, 1986.

SANTOS, Angela Moulin Simões Penalva. Descentralização e autonomia municipal: uma análise das transformações institucionais no federalismo brasileiro. Geo UERJ - Ano 14, no. 23, v. 2, 2o semestre de 2012 p. 825-852

SILVA, José Afonso da. Curso de Direito Constitucional. 35. ed. São Paulo: Malheiros, 2011.

Trabalho enviado em 03 de julho de 2016.

Aceito em 17 de julho de 2016. 